\title{
Serum thyroid stimulating hormone in assessment of severity of tissue hypothyroidism in patients with overt primary thyroid failure: cross sectional survey
}

\author{
Christian Meier, Peter Trittibach, Merih Guglielmetti, Jean-Jacques Staub, Beat Müller
}

Primary hypothyroidism is a graded phenomenon with a wide spectrum of severity between subclinical hypothyroidism and overt hypothyroidism. Patients with biochemically severe hypothyroidism may present with only mild clinical manifestations, whereas some patients with moderate changes in thyroid hormones may present with severe signs of tissue hypothyroidism. ${ }^{1}$ The measurement of pituitary thyroid stimulating hormone (TSH) is the most sensitive test for early diagnosis of primary hypothyroidism. The magnitude of elevation of TSH is commonly believed to correspond to the severity of tissue hypothyroidism. We aimed to evaluate the value of measuring serum TSH in assessing the severity of tissue hypothyroidism in patients with overt hypothyroidism.

\section{Methods and results}

We recruited 49 patients with overt hypothyroidism (TSH $>20 \mathrm{mU} /$ l, free thyroxine $<8.0 \mathrm{pmol} / \mathrm{l}$; mean age 56.6 (SD 12.1) years) from a cohort of female patients followed prospectively in the thyroid research unit of the endocrine outpatient clinic. The patients had underlying thyroid disorders of chronic autoimmune thyroiditis $(n=30)$, treated Graves' hyperthyroidism (radioiodine or surgery; 16), thyroidectomy for simple goitre (2), and treated toxic adenoma (1). We excluded non-thyroidal illnesses in all women. In addition to measuring TSH and peripheral thyroid hormones (free thyroxine and triiodothyronine) we assessed clinical and metabolic markers of hypothyroidism (clinical score, ankle reflex time, creatine kinase, total cholesterol) to evaluate thyroid hormone action at the tissue level. ${ }^{1-3}$ To estimate the association between thyroid hormones and markers of tissue hypothyroidism we correlated TSH and thyroid hormone concentrations with the different tissue parameters. The ethics committee for human studies approved the study.

The table summarises the correlation analyses of thyroid hormone concentrations with different mark- ers of tissue hypothyroidism. In contrast to the good correlations with both circulating thyroid hormones, we found no correlation or only weak correlations with serum TSH.

We then used the Mann-Whitney $\mathrm{U}$ test to analyse patients' data in relation to the severity of tissue hypothyroidism as assessed by ankle reflex time (patients with moderate prolongation $(410-550 \mathrm{~ms} ; \mathrm{n}=15) \mathrm{com}$ pared with patients with severe prolongation $(>550$ $\mathrm{ms}$; 15)). Free thyroxine concentrations declined significantly between these groups (from median 5.5 (range 1.9-7.8) $\mathrm{pmol} / \mathrm{l}$ to 2.5 (1.8-3.5) $\mathrm{pmol} / \mathrm{l}$; $\mathrm{P}=0.001)$, as did triiodothyronine $(1.0(0.7-1.6) \mathrm{nmol} / \mathrm{l}$ to $0.8(0.2-1.1) \mathrm{nmol} / \mathrm{l} ; \mathrm{P}=0.002)$. We also found an impairment of the clinical score (from 5 (3-11) points to 8.5 (6-11) points; $\mathrm{P}=0.005)$, creatine kinase (144.0 (62.0-362.0) U/1 to $566.0(229.0-2170) \mathrm{U} / 1 ; \mathrm{P}<0.001)$, and total cholesterol $(7.63(5.7-11.2) \mathrm{mmol} / \mathrm{l}$ to 9.4 (7.8-14.2) $\mathrm{mmol} / \mathrm{l} ; \mathrm{P}=0.003)$. In contrast, we found no difference in TSH concentrations between the groups (from 42.0 (26.1-137.0) mU/1 to 53.8 (23.6-95.3) mU/l; $\mathrm{P}=0.44)$.

\section{Comment}

$\mathrm{TSH}$ is a poor measure for estimating the clinical and metabolic severity of primary overt thyroid failure. This is in sharp contrast to the high diagnostic accuracy of TSH measurement for early diagnosis of hypothyroidism.

We found no correlations between the different parameters of target tissues and serum TSH. Our findings are in accordance with a cross sectional study showing only a modest correlation between TSH and the percentage of positive hypothyroid symptoms ${ }^{4}$ and data showing discordant responses between the pituitary and peripheral target tissues in patients treated with L-triiodothyronine. ${ }^{5}$ We assume that secretion of TSH is driven by maximal stimulation, with no further increase occurring with greater severity of hypothyroidism. Therefore, the biological effects of
Editorial by Toft and Beckett

Division of Endocrinology, Department of Medicine,

University Hospital, CH-4031 Basle, Switzerland

Christian Meier senior registrar in endocrinology

Peter Trittibach clinical research fellow Merih Guglielmetti statistician

Jean-Jacques Staub emeritus professor of endocrinology

Beat Müller head of division Correspondence to: C Meier cmeier@uhbs.ch

BMJ 2003;326:311-2

Basic descriptive data and correlation analyses of thyroid hormone concentrations with different markers of tissue hypothyroidism in 49 patients with overt thyroid failure

\begin{tabular}{|c|c|c|c|c|c|c|c|}
\hline \multirow[b]{2}{*}{ Marker } & \multirow[b]{2}{*}{ Median (range) } & \multicolumn{2}{|c|}{ Correlation* with TSH } & \multicolumn{2}{|c|}{$\begin{array}{l}\text { Correlation* with } \\
\text { free thyroxine }\end{array}$} & \multicolumn{2}{|c|}{$\begin{array}{l}\text { Correlation* with } \\
\text { triiodothyronine }\end{array}$} \\
\hline & & $r$ value & $P$ value & $r$ value & $P$ value & $r$ value & $P$ value \\
\hline Ankle reflex timeł $(\mathrm{ms})(\mathrm{n}=49)$ & $440(310-815)$ & 0.32 & 0.02 & -0.71 & $<0.0001$ & -0.73 & $<0.0001$ \\
\hline Clinical score§ (points) $(n=44)$ & $5(0-11)$ & 0.17 & 0.28 & -0.62 & $<0.0001$ & -0.53 & $<0.001$ \\
\hline Total cholesterolף $(\mathrm{mmol} / \mathrm{l})(\mathrm{n}=44)$ & $7.0(3.4-14.2)$ & 0.04 & 0.81 & -0.58 & $<0.0001$ & -0.39 & $<0.01$ \\
\hline Creatine kinasefl (U/I) $(n=47)$ & 151 (28 to 2170 ) & 0.20 & 0.19 & -0.61 & $<0.0001$ & -0.55 & $<0.001$ \\
\hline
\end{tabular}

TSH=thyroid stimulating hormone.

*Correlations calculated by Spearman's rank correlation analysis.

†Measured by saturation analysis (reference range 8.0-24.1 pmol/l).

†Reference range 290-410 ms; measured as a mean of six readings by photomotogram with an achillometer recording three tracings on each side. ${ }^{2}$

$\S$ Measure of degree of clinical hypothyroidism. ${ }^{1}$

ๆ|Measured enzymatically; reference ranges 40-160 U/I for creatine kinase and 3.0-5.2 mmol// for total cholesterol. 
thyroid hormones at the peripheral tissues-and not TSH concentrations-reflect the clinical severity of hypothyroidism. A judicious initiation of thyroxine treatment should be guided by clinical and metabolic presentation and thyroid hormone concentrations (free thyroxine) and not by serum TSH concentrations.

We thank the laboratory staff of the division of endocrinology (Maya Kunz, Sylvia Alscher, Ursula Schild) for performing the biochemical and technical analyses.

Contributors: CM, J-JS, and BM were involved in the conceptual design, interpretation of data, critical revision of the paper, and approval of the final version. CM, PT, and MG were involved in data collection and analysis. BM and J-JS are the guarantors.

Funding: Swiss Research Foundation (grants 32.27866.89, 32.37792.93, and 32.37792.98); unconditional research grants from Sandoz Research and Roche Research Foundations (to J-JS), the Sonderprogramm zur Förderung des akademischen
Nachwuchses der Universität Basel, and the Nora van Meeuwen-Häfliger Foundation (to BM).

Competing interests: None declared.

1 Zulewski H, Muller B, Exer P, Miserez AR, Staub JJ. Estimation of tissue hypothyroidism by a new clinical score: evaluation of patients with hypothyroidism by a new clinical score: evaluation of patients with
various grades of hypothyroidism and controls. J Clin Endocrinol Metab various grades

2 Staub JJ, Althaus BU, Engler H, Ryff AS, Trabucco P, Marquardt K, et al. Spectrum of subclinical and overt hypothyroidism: effect on thyrotropin, prolactin, and thyroid reserve, and metabolic impact on peripheral target tissues. Am J Med 1992;92:631-42.

3 Franklyn JA, Daykin J, Betteridge J, Hughes EA, Holder R, Jones SR, et al. Thyroxine replacement therapy and circulating lipid concentrations. Clin Endocrinol (Oxf) 1993;38:453-9.

4 Canaris GJ, Steiner JF, Ridgway EC. Do traditional symptoms of hypothyroidism correlate with biochemical disease? J Gen Intern Med 1997; 12:544-50

5 Ridgway EC, Cooper DS, Walker H, Daniels GH, Chin WW, Myers G, et al. Therapy of primary hypothyroidism with L-triiodothyronine: discordant cardiac and pituitary responses. Clin Endocrinol (Oxf) 1980;13:479-88. (Accepted 2 September 2002)

\title{
Cardiac troponin $\mathrm{T}$ in the severity assessment of patients with pulmonary embolism: cohort study
}

\author{
Karin Janata, Michael Holzer, Anton N Laggner, Marcus Müllner
}

Universitätsklinik für Notfallmedizin, Allgemeines Krankenhaus Wien, Währinger Gürtel $18-20 / 6 \mathrm{D}, \mathrm{A}-1090$ Vienna, Austria Karin Janata consultant

Michael Holzer specialist registrar Anton N Laggner professor

Marcus Müllner clinical epidemiologist Correspondence to: M Mullner marcus.muellner@ univie.ac.at

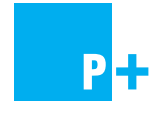

An extra table appears on bmj.com
Right ventricular function is an important prognostic factor for pulmonary embolism. ${ }^{1}$ Massive pulmonary embolism may lead to right ventricular failure, reduced left ventricular output, and even death. ${ }^{2}$ Cardiac troponins are routinely applied markers of minor and major myocardial damage in patients with acute coronary syndromes. In small case series, troponin concentrations were raised in patients with massive pulmonary embolism. ${ }^{34}$ The role of troponin as a prognostic factor is, however, unclear. We assessed the association between serum concentrations of cardiac troponin $\mathrm{T}$ and severity of pulmonary embolism as well as the role of troponin $\mathrm{T}$ as a predictor of mortality.

\section{Participants, methods, and results}

We assessed 136 consecutive patients who were admitted to the emergency department of a tertiary care university hospital between December 1999 and November 2001 with pulmonary embolism, confirmed by computed tomography or scintigraphy. Two patients with terminal illness and seven patients admitted after cardiac arrest out of hospital were excluded. In 106 patients troponin concentrations were determined in the first 12 hours after admission (Elecsys 2010; Roche, Mannheim, Germany). The severity of the event was classified according to the grading system by Grosser (see table A on bmj.com). ${ }^{5}$ Right ventricular strain in the electrocardiogram was defined as right bundle branch block, $\mathrm{T}$ wave inversion in precordial leads, or $S_{1} Q_{3} T_{3}$ pattern. We used Spearman's correlation and the Wilcoxon rank sum test and constructed a receiver operating characteristic curve based on sensitivities and specificities, using various troponin values as cut offs to determine mortality in hospital. We used routine data; studies using such data are not routinely reviewed by the local ethical review board.

The median age of patients was 60 (interquartile range 43-72) years; 74 (58\%) were female. Six had fulminant pulmonary embolism, in 37 it was massive, in 62 it was submassive, and in one it was minor. With increasing severity of pulmonary embolism troponin concentrations also increased $(r=0.56, \mathrm{P}<0.001)$. The median troponin concentration in patients with signs of right ventricular strain in the electrocardiogram was $0.03 \mathrm{ng} / \mathrm{ml}$ (interquartile range $<0.01$ to 0.06 ) and in patients without these signs $<0.01 \mathrm{ng} / \mathrm{ml}$ $(<0.01$ to $<0.01, \mathrm{P}<0.001)$. Ninety three patients underwent echocardiography, of whom $63(68 \%)$ had signs of right ventricular strain ${ }^{1}$; the median troponin concentration in patients with signs of right ventricular strain was $0.03 \mathrm{ng} / \mathrm{ml}$ compared with $<0.01$ $\mathrm{ng} / \mathrm{ml}(\mathrm{P}<0.001)$ in patients without right ventricular strain.

Five of 106 patients with troponin measurements died in hospital (5\%); troponin concentrations were higher in patients who died than in survivors $(0.18$ $\mathrm{ng} / \mathrm{ml}(0.09$ to 0.18$) v<0.01 \mathrm{ng} / \mathrm{ml}(<0.01$ to 0.03$)$, $\mathrm{P}<0.001)$. A cut-off value for troponin of $0.09 \mathrm{ng} / \mathrm{ml}$ was a suitable predictor for death in hospital (figure). The area under the curve was 0.92 (95\% confidence interval 0.82 to 1.0 ), and the cut-off value had a sensitivity of $0.80(0.49$ to 1.0$)$ and a specificity of 0.92 $(0.87$ to 0.97$)$. The negative predictive value was 0.99 (0.93 to 1.00$)$ and the positive predictive value 0.34 (0.10 to 0.59$)$.

\section{Comment}

Raised concentrations of troponin $\mathrm{T}$ are associated with a higher in-hospital mortality in patients with pulmonary embolism. The major limitation of this study is that we do not know in how many patients pulmonary 